\title{
Financial Incentives and Cervical Cancer Screening Participation in Ontariós Primary Care Practice Models
}

\author{
Incitatifs financiers et participation au dépistage pour le cancer \\ du col de l'utérus dans les modèles de soins primaires en Ontario
}

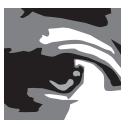

CIARA PENDRITH, MSC

Department of Epidemiology and Biostatistics

Schulich School of Medicine and Dentistry

Western University

London, ON

AMARDEEP THIND, MD, PHD

Department of Epidemiology and Biostatistics

Centre for Studies in Family Medicine

Schulich Interfaculty Program in Public Health

Schulich School of Medicine and Dentistry

Western University

London, ON

Institute for Clinical Evaluative Sciences

Toronto, ON

GREGORY S. ZARIC, PHD

Ivey School of Business

Department of Epidemiology and Biostatistics

Schulich School of Medicine and Dentistry

Western University

London, ON

SISIRA SARMA, PHD

Department of Epidemiology and Biostatistics

Schulich School of Medicine and Dentistry

Western University

London, ON

Institute for Clinical Evaluative Sciences

Toronto, ON 


\begin{abstract}
Objectives: The primary objective of this paper is to compare cervical cancer screening rates of family physicians in Ontario's two dominant reformed practice models, Family Health Group (FHG) and Family Health Organization (FHO), and traditional fee-for-service (FFS) model. Both reformed models formally enrol patients and offer extensive pay-for-performance incentives; however, they differ by remuneration for core services (FHG is FFS; FHO is capitated). The secondary objective is to estimate the average and marginal costs of screening in each model. Methods: Using administrative data on 7,298 family physicians and their 2,083,633 female patients aged 35-69 eligible for cervical cancer screening in 2011, we assessed screening rates after adjusting for patient and physician characteristics. Predicted screening rates, fees and bonus payments were used to estimate the average and marginal costs of cervical cancer screening. Results: Adjusted screening rates were highest in the FHG (81.9\%), followed by the FHO (79.6\%), and then the traditional FFS model (74.2\%). The cost of a cervical cancer screening was $\$ 18.30$ in the FFS model. The estimated average cost of screening in the FHGs and FHOs were $\$ 29.71$ and $\$ 35.02$, respectively, while the corresponding marginal costs were $\$ 33.05$ and $\$ 39.06$. Discussion: We found significant differences in cervical cancer screening rates across Ontario's primary care practice models. Cervical screening rates were significantly higher in practice models eligible for incentives (FHGs and FHOs) than the traditional FFS model. However, the average and marginal cost of screening were lowest in the traditional FFS model and highest in the FHOs.
\end{abstract}

\title{
Résumé
}

Objectifs: Le premier objectif de cet article est de comparer les taux de dépistage du cancer du col de l'utérus par les médecins de famille dans les deux principaux modèles de prestation de services en Ontario, les groupes de santé familiale (GSF) et les organismes de santé familiale (OSF), et selon le modèle traditionnel du paiement à l'acte (PA). Ces modèles réformés enrôlent officiellement les patientes et offrent de généreux incitatifs pour le rendement; cependant, ils diffèrent pour ce qui est de la rémunération des services de base (les GSF fonctionnent selon le PA et les OSF fonctionnent selon le paiement par capitation). Le deuxième objectif est d'évaluer les coûts moyen et marginal du dépistage dans chacun des modèles. Méthode : À l'aide des données administratives de 7298 médecins de famille et leurs 2083633 patientes âgées de 35 à 69 ans admissibles pour le dépistage du cancer du col de l'utérus en 2011, nous avons estimé les taux de dépistage après ajustement en fonction des caractéristiques des patientes et des médecins. Le calcul des taux de dépistage, des coûts et des primes sést fait en estimant les coûts moyen et marginal du dépistage du cancer du col de l'utérus.

Résultats : Les taux de dépistage ajustés étaient plus élevés dans les GSF (81,9\%), suivi des OSF (79,6 \%) et du modèle traditionnel du PA (74,2 \%). Le coût d'un dépistage du cancer du col de l'utérus s'élevait à 18,30 \$ dans le modèle du PA. Les coûts moyens estimés du dépistage dans les GSF et les OSF s'élevaient, respectivement, à 29,71 \$ et à 35,02 \$, alors que les coûts moyens correspondants étaient de 33,05 \$ et 39,06 \$. 
Discussion: Nous avons observé des différences notables dans les taux de dépistage du cancer du col de l'utérus parmi les modèles de prestations de soins primaires en Ontario. Les taux de dépistage du cancer du col de l'utérus étaient significativement plus élevés dans les modèles de prestation de services admissibles aux incitatifs (GSF et OSF) que dans le modèle traditionnel du PA. Cependant, les coûts moyen et marginal du dépistage étaient plus bas dans le modèle traditionnel du PA et plus élevé dans les OSF.

\section{Introduction}

Cervical cancer is the third most frequent cancer in women worldwide and is the 11th most commonly diagnosed cancer among Canadian women (Dickinson et al. 2012; Ferlay et al. 2010; Jemal et al. 2011). Following the introduction of universal health insurance in Canada in the early 1970s, the uptake of cervical cancer screening with the Papanicolaou (Pap) test increased considerably (Dickinson et al. 2012). Cervical cancer incidence and mortality rates declined by 58\% and 71\%, respectively, between 1972 and 2006 in Canada, which is largely attributed to increased screening participation (Dickinson et al. 2012). It takes several years for infection with human papillomavirus (HPV) to progress to invasive cervical cancer, so with timely screening and follow-up of abnormal test results, many cancer cases and deaths are preventable (Schiffman et al. 2007). Despite the progress in cervical cancer screening in Ontario, approximately 610 women were diagnosed with cervical cancer and 150 women died from it in 2013 (Canadian Cancer Society 2013). Among incident cases in Ontario, nearly $40 \%$ had no record of screening within the four years prior to diagnosis (Spayne et al. 2008).

Ontario guidelines recommend that women, who are or ever have been sexually active between 21 and 69 years, be screened with a Pap smear once every three years (Canadian Task Force on Preventive Health Care et al. 2013; Cancer Care Ontario 2014; Murphy et al. 2012). The Ontario Ministry of Health and Long-Term Care (MOHLTC) recently set a target rate of 85\% screening participation; however, during 2009-2011 less than 65\% of women aged 20-69 were screened (Cancer Care Ontario 2014). Women who are never or inadequately screened have a heightened risk of cervical cancer, advanced cancer and cervical cancer-related mortality (Andrae et al. 2008; Macgregor et al. 1994; Spence et al. 2007). Consequently, failure to screen at the recommended interval may have both health and economic consequences. Thus, family physicians play an important role in educating female patients, who are at risk for cervical cancer, about the benefits of cervical cancer screening with a Pap test every three years.

In an effort to strengthen Ontario's primary care system and improve delivery of preventive healthcare services by family physicians, the government of Ontario implemented primary care reforms in the early 2000s. Several new primary care practice models featuring formal patient enrolment and alternative payment arrangements were introduced in the mid-2000s. Financial incentives for physicians and changes in the mode of physician remuneration were two mechanisms by which the government of Ontario aimed to improve the delivery and uptake of a basket of preventive care 
services. During this period, the majority of family physicians transitioned their practices from the traditional fee-for-service (FFS) model to two reformed practice models; the Family Health Group (FHG) and the Family Health Organization (FHO) (Glazier et al. 2012; Kralj and Kantarevic 2013; Office of the Auditor General of Ontario 2011). The FHG and FHO mainly differ by remuneration for core services: FHG physicians receive FFS payments, whereas $\mathrm{FHO}$ physicians receive capitation payments for core services provided to enrolled patients; otherwise, the FHG and FHO are quite similar and share many key elements that are not available in the traditional FFS model, such as patient rostering and pay-for-performance incentives (Sweetman and Buckley 2014). Patient rostering formalizes the doctor-patient relationship: patients agree to seek care from their physician or practice, while physicians commit to providing ongoing, comprehensive primary care (Kralj and Kantarevic 2013). This formal arrangement is not present in the FFS model. The Cumulative Preventive Care Bonus for Pap smear, based on the proportion of enrolled patients aged 35 to 69 years, who received a Pap smear within a 30-month period, is: $\$ 220$ for $60 \%$, $\$ 440$ for $65 \%$, $\$ 660$ for $70 \%, \$ 1,320$ for $75 \%$ and $\$ 2,200$ for $80 \%$ screened. For a detailed description of primary care practice models in Ontario, please see Pendrith (2014) and Sweetman and Buckley (2014).

Previous studies have shown mixed effects of Ontario's preventive care bonuses with one study reporting a significant increase in cervical cancer screening participation ( $\mathrm{Li}$ et al. 2014) and another finding no significant change in screening trends after the introduction of incentives (Kiran et al. 2014). Although Kiran et al. (2014) looked at the impact of incentives on screening rates over a 10-year period, they did not explicitly examine the role of remuneration and estimate marginal costs of screening. The objectives of this study are to: (1) determine if cervical cancer screening rates differ among the FFS, FHG and FHO models; and (2) estimate the average and marginal costs of screening per patient in the three primary care practice models.

\section{Methods}

We obtained our study data from population-based Ontario health administrative databases linked with unique, encoded identifiers and analyzed at the Institute for Clinical Evaluative Sciences (ICES). Full-time comprehensive family physicians in a FFS, FHG or FHO practice on March 31, 2011 (study index date) were selected from the Corporate Provider Database (CPDB). Physicians with a narrow scope of practice (e.g., sports medicine, counselling, etc.) were identified by the proportion of office visits or core services of total billings and excluded. Female patients aged 35-69 of included FHG and FHO physicians were identified from the Client Agency Program Enrolment tables, while those of FFS physicians were identified from Ontario Health Insurance Plan (OHIP) claims using a validated algorithm (Hutchison et al. 1997). According to this algorithm, a FFS physician's patient population was defined as all patients for whom they billed at least one office visit in the preceding year, or at least one service in each of the preceding two years for that patient (Hutchison et al. 1997). Patients with claims from multiple FFS physicians were assigned to the physician who billed the most office visits, or the most recent office visit in the case of ties (Hutchison et al. 1997). We excluded women with evidence of prior gynecological cancer diagnoses in the Ontario Cancer Registry, hysterectomy recorded in the Canadian Institute for Health Information Discharge 
Abstract Database (CIHI-DAD) or infection with HIV in the ICES HIV database (Antoniou et al. 2011). We obtained patient age, rural/urban residence status and neighbourhood socio-economic status (SES) from the ICES databases on index date. Neighbourhood SES was obtained using the Ontario Marginalization Index, which uses a composite of indicators at the census dissemination area to capture SES in four domains: material deprivation, residential instability, dependency and ethnic concentration (Matheson et al. 2012). Dependency was excluded from the regression analysis, because it utilizes several of the same indicators as material deprivation and, thus, is highly correlated with this domain. We also obtained physician gender, experience (years since graduation) and number of patients eligible for cervical cancer screening on March 31, 2011.

Patient-level screening status was assessed from the OHIP claims database using a validated billing code algorithm available at ICES (Lofters et al. 2010). Physician screening rate was defined as the number of eligible women receiving a Pap smear in the 30 months prior divided by all eligible women in their practice. FHG physicians with a minimum of 650 enrolled patients and $\mathrm{FHO}$ physicians were eligible to claim bonuses, which were identified from OHIP claims in 2010/11 for a single fiscal year.

We compared patient- and physician-level characteristics across practice models using analysis of variance (ANOVA) and the Chi-square statistic, where appropriate. Multivariable fractional logit regression models were used to estimate physician screening rates. The fractional logit/probit model is the most appropriate model when the outcome of interest is bounded by $0 \%$ and $100 \%$ (Papke and Woodbridge 1996). We controlled for physician characteristics and patient-level variables, which were aggregated to the physician practice-level using group means or proportions. Measures of neighbourhood SES were obtained by calculating the proportion of a physician's patients living in quintiles 1 and 2, which represent the least marginalized or highest SES areas. Three regression models were fit to compare the adjusted screening rates of the following pairs of practice models: (1) FFS vs. FHG; (2) FHO vs. FHG; and (3) FFS vs. FHO. The marginal effects of the practice model were estimated using the method of recycled predictions (Muller and MacLehose 2014).

Screening cost estimates included delivery costs from the provincial fee schedule (Government of Ontario 2014) and bonus costs for FHG and FHO physicians. We assumed that all Pap smears were performed outside of the hospital and, therefore, delivery costs included both the procedure fee (\$6.75) and the laboratory add-on fee paid to physicians delivering Pap smears outside of hospital (\$11.55) (Government of Ontario 2014). Pap smears are covered by capitation payments in the FHO, so FHO physicians do not receive the fee paid to FFS or FHG physicians. We assumed that the Pap smear procedure fee is built into capitation payments and the unit cost to deliver a Pap smear $(\$ 18.30)$ was the same across all practice models in our base case scenario. Sensitivity analyses were performed where the Pap smear delivery unit cost in the FHO was estimated at $\$ 0, \$ 5, \$ 10, \$ 15$ and $\$ 20$ and the corresponding average and marginal costs were calculated. Bonuses claimed by physicians in 2010/2011 were summed and added to delivery costs to estimate the total costs of screening in a given year. The average cost of screening per woman was estimated by dividing the total annual cost by the annual number of patients screened. Marginal costs were estimated by dividing the additional payments in the FHG and FHO models by the additional volume of women screened relative to the FFS. 
Financial Incentives and Cervical Cancer Screening Participation in Ontario's Primary Care Practice Models

All analyses were performed using Statistical Analysis System (SAS) 9.2 at ICES

Western, a satellite site of ICES affiliated with Western University.

\section{Results}

There were 7,298 eligible physicians with a total of 2,083,633 female patients aged 35-69 eligible for cervical cancer screening. FFS physicians were more likely to be male, more experienced and have fewer eligible patients than physicians in FHG or FHO (Table 1). Patients of FHO physicians were more likely to reside in a rural area and have greater neighbourhood SES.

TABLE 1. Characteristics of study physicians and patients and unadjusted screening rates

\begin{tabular}{|c|c|c|c|c|}
\hline & FFS & FHG & FHO & Total \\
\hline \multicolumn{5}{|l|}{ Physician characteristics } \\
\hline $\mathrm{N}(\%)$ & ।, $172(16.1 \%)$ & $2,847(39.0 \%)$ & $3,279(44.9 \%)$ & $7,298(100 \%)$ \\
\hline Female, \%* & $36.3 \%$ & $40.9 \%$ & $42.1 \%$ & $40.7 \%$ \\
\hline \multicolumn{5}{|c|}{ Experience (years since graduation), \%* } \\
\hline$<10$ years & $15.8 \%$ & $7.1 \%$ & $10.0 \%$ & $9.8 \%$ \\
\hline $10-19$ years & $15.3 \%$ & $21.6 \%$ & $22.6 \%$ & $21.0 \%$ \\
\hline$\geq 20$ years & $68.9 \%$ & $71.3 \%$ & $67.4 \%$ & $69.2 \%$ \\
\hline \multicolumn{5}{|c|}{ Number of patients in Pap smear target population, \%* } \\
\hline$\leq 100$ women & $35.4 \%$ & $14.2 \%$ & $4.5 \%$ & $13.3 \%$ \\
\hline$>100$ women & $64.6 \%$ & $85.8 \%$ & $95.5 \%$ & $86.7 \%$ \\
\hline \multicolumn{5}{|l|}{ Screening rate } \\
\hline Mean $(95 \% \mathrm{Cl})$ & $71.9 \%(71.7,72.1)$ & $82.6 \%(82.5,82.7)$ & $78.9 \%(78.8,79.0)$ & $79.2 \%(79.1,79.3)$ \\
\hline \multicolumn{5}{|l|}{ Patient characteristics } \\
\hline $\mathrm{N}(\%)$ & $216,609(10.4 \%)$ & $833,706(40.0 \%)$ & ।,033,3। $8(49.6 \%)$ & $2,083,633(100 \%)$ \\
\hline Mean age & 49.4 & 49.6 & 50.4 & 50.0 \\
\hline Rural, \%* & $6.1 \%$ & $2.2 \%$ & $7.5 \%$ & $5.2 \%$ \\
\hline \multicolumn{5}{|c|}{ Socio-Economic status: Ontario Marginalization Index Quintiles, \% } \\
\hline \multicolumn{5}{|l|}{ Material deprivation*s } \\
\hline $\begin{array}{l}\text { QI (least marginalized; } \\
\text { highest SES) }\end{array}$ & $23.5 \%$ & $28.9 \%$ & $29.4 \%$ & $28.5 \%$ \\
\hline Q2 & $20.9 \%$ & $23.7 \%$ & $24.2 \%$ & $23.6 \%$ \\
\hline Q3 & $20.1 \%$ & $19.5 \%$ & $19.6 \%$ & $19.6 \%$ \\
\hline Q4 & $17.8 \%$ & $14.8 \%$ & $15.0 \%$ & $15.2 \%$ \\
\hline $\begin{array}{l}\text { Q5 (most marginalized; } \\
\text { lowest SES) }\end{array}$ & $16.4 \%$ & $12.4 \%$ & $11.0 \%$ & $12.1 \%$ \\
\hline Missing & $1.4 \%$ & $0.7 \%$ & $0.8 \%$ & $0.8 \%$ \\
\hline
\end{tabular}


TABLE 1. Continued

\begin{tabular}{|c|c|c|c|c|}
\hline & FFS & FHG & FHO & Total \\
\hline \multicolumn{5}{|l|}{ Dependency*\$ } \\
\hline $\begin{array}{l}\text { QI (least marginalized; } \\
\text { highest SES) }\end{array}$ & $26.6 \%$ & $28.7 \%$ & $20.8 \%$ & $24.5 \%$ \\
\hline Q2 & $23.8 \%$ & $26.2 \%$ & $22.6 \%$ & $24.1 \%$ \\
\hline Q3 & $18.9 \%$ & $18.4 \%$ & $20.7 \%$ & $19.6 \%$ \\
\hline Q4 & $15.0 \%$ & $13.6 \%$ & $17.8 \%$ & $15.8 \%$ \\
\hline $\begin{array}{l}\text { Q5 (most marginalized; } \\
\text { lowest SES) }\end{array}$ & $14.4 \%$ & $12.4 \%$ & $17.3 \%$ & $15.0 \%$ \\
\hline Missing & $1.4 \%$ & $0.7 \%$ & $0.8 \%$ & $0.8 \%$ \\
\hline \multicolumn{5}{|l|}{ Ethnic concentration*\$ } \\
\hline $\begin{array}{l}\text { QI (least marginalized; } \\
\text { highest SES) }\end{array}$ & $8.4 \%$ & $6.5 \%$ & $14.2 \%$ & $10.5 \%$ \\
\hline Q2 & $11.0 \%$ & $10.4 \%$ & $19.7 \%$ & $15.1 \%$ \\
\hline Q3 & $13.9 \%$ & $13.9 \%$ & $20.7 \%$ & $17.3 \%$ \\
\hline Q4 & $19.6 \%$ & $20.7 \%$ & $22.0 \%$ & $21.2 \%$ \\
\hline $\begin{array}{l}\text { Q5 (most marginalized; } \\
\text { lowest SES) }\end{array}$ & $45.8 \%$ & $47.8 \%$ & $22.6 \%$ & $35.1 \%$ \\
\hline Missing & $1.4 \%$ & $0.7 \%$ & $0.8 \%$ & $0.8 \%$ \\
\hline Screened, \%* & $73.1 \%$ & $83.9 \%$ & $78.8 \%$ & $80.2 \%$ \\
\hline
\end{tabular}

FFS $=$ fee-for-service; $F H G=$ Family Health Group; $F H O=$ Family Health Organization; $\mathrm{Cl}=$ confidence interval. ${ }^{*} \mathrm{p}<0.00 \mathrm{I},{ }^{\S} \mathrm{Q} \mathrm{I}-\mathrm{Q} 5$ are quantiles $(\mathrm{Q} \mathrm{I}$ is the least-marginalized quantile and $\mathrm{Q} 5$ is the most-marginalized quantile)

Overall, $80.2 \%$ of women had at least one Pap smear, and FHG patients were most likely to be screened (Table 2; Figure 1). The primary care practice model was associated with screening rate after adjusting for patient- and physician-level characteristics. Compared with FFS and FHO physicians, the mean adjusted screening rate of FHG physicians was $7.7 \%$ $(p<0.0001)$ and $2.3 \%(p<0.0001)$ higher, respectively. The mean adjusted screening rate of FHO physicians was $6.2 \%$ higher than that of FFS physicians $(p<0.0001)$.

In 2010/11, 55.8\% and 81\% of FHG and FHO physicians, respectively, claimed a bonus of which $65 \%$ claimed $\$ 2,200$ (Table 3). Bonuses to FHG and FHO physicians totaled $\$ 7.195$ million in that fiscal year. The total one-year costs of cervical cancer screening ranged from $\$ 965,764$ in the FFS model to $\$ 9,498,350$ in the FHO. The FFS model is associated with the lowest cost per woman screened (the unit cost of $\$ 18.30$ ). The costs per woman screened, including bonus payments, in the FHG and FHO were $\$ 29.71$ and $\$ 35.02$, respectively. In sensitivity analysis, the average screening cost per woman in the FHO ranged from $\$ 16.72$ to $\$ 36.72$. The marginal cost was $\$ 18.30$ in the FFS, $\$ 33.05$ in the FHG and $\$ 39.06$ in the FHO in our base case scenario. The sensitivity analysis showed that the marginal screening cost in the FHO could range from $\$ 18.56$ to $\$ 41.17$. 
Financial Incentives and Cervical Cancer Screening Participation in Ontario's Primary Care Practice Models

TABLE 2. Regression results and mean predicted screening rates

\begin{tabular}{|c|c|c|c|}
\hline Regression model & I: FFS-FHG & 2: FHO-FHG & 3: FFS-FHO \\
\hline \multicolumn{4}{|l|}{ Characteristic, $\beta$ (SE) } \\
\hline Intercept & $0.046(0.423)$ & $1.698(0.461)^{\dagger}$ & $-0.229(0.453)$ \\
\hline Model & $0.463(0.031)^{\ddagger}$ & $0.151(0.023)^{\ddagger}$ & $0.349(0.034)^{\ddagger}$ \\
\hline Mean patient age & $0.009(0.009)$ & $-0.020(0.009)^{\S}$ & $0.016(0.009)^{*}$ \\
\hline Percentage rural & $-0.021(0.117)$ & $-0.44(0.092)$ & $0.250(0.066)^{\dagger}$ \\
\hline Percentage deprivation Q1 \& Q2 & $0.651(0.094)^{\ddagger}$ & $0.749(0.097)^{\ddagger}$ & $0.798(0.106)^{\ddagger}$ \\
\hline Percentage ethnic con. Q। \& Q2 & $-0.682(0.102)^{\ddagger}$ & $-0.756(0.075)^{\ddagger}$ & $-0.832(0.073)^{\ddagger}$ \\
\hline Percentage instability Q I \& Q2 & $0.113(0.103)$ & $0.142(0.070)^{5}$ & $-0.067(0.010)$ \\
\hline Female PCP & $0.496(0.029)^{\ddagger}$ & $0.543(0.023)^{\ddagger}$ & $0.551(0.025)^{\ddagger}$ \\
\hline$<10$ years' experience & $-0.083(0.032)^{5}$ & $0.010(0.026)$ & $0.004(0.028)$ \\
\hline $10-19$ years' experience & $-0.109(0.046)^{5}$ & $0.043(0.041)$ & $-0.09(0.037)^{\S}$ \\
\hline $\begin{array}{l}\leq 100 \text { patients in Pap smear target } \\
\text { population }\end{array}$ & $0.221(0.039)^{\ddagger}$ & $0.346(0.052)^{\ddagger}$ & $0.093(0.045)^{*}$ \\
\hline \multicolumn{4}{|c|}{ Mean predicted screening rate, $\%$ ( $95 \%$ confidence interval) } \\
\hline $\mathrm{FHG}$ & $81.9 \%(81.7,82.0)$ & $81.9 \%(81.7,82.0)$ & - \\
\hline $\mathrm{FHO}$ & - & $79.6 \%(79.4,79.8)$ & $78.8 \%(78.6,78.9)$ \\
\hline FFS & $74.2 \%(73.9,74.4)$ & - & $72.5 \%(72.3,72.7)$ \\
\hline Difference & $7.7 \%(7.6,7.7)$ & $2.3 \%(2.3,2.3)$ & $6.2 \%(6.2,6.3)$ \\
\hline
\end{tabular}

FFS = fee-for-service; FHG = Family Health Group; FHO = Family Health Organization; $\mathrm{SE}=$ standard error; $\mathrm{Q}$ I \& Q2 = lowest quintiles; PCP = primary care physician ${ }^{*} p<0.1 ;{ }^{5} p<0.05 ; " p<0.01 ;{ }^{\dagger} p<0.001 ;{ }^{*} p<0.0001$

FIGURE 1. (a) Mean unadjusted physician practice rate by primary care practice model; (b) predicted physician practice screening rates from regression model I (FFS vs. FHG); (c) predicted physician practice screening rates from regression model 2 (FHG vs. FHO); (d) predicted physician practice screening rates from regression model 3 (FFS vs. FHO)

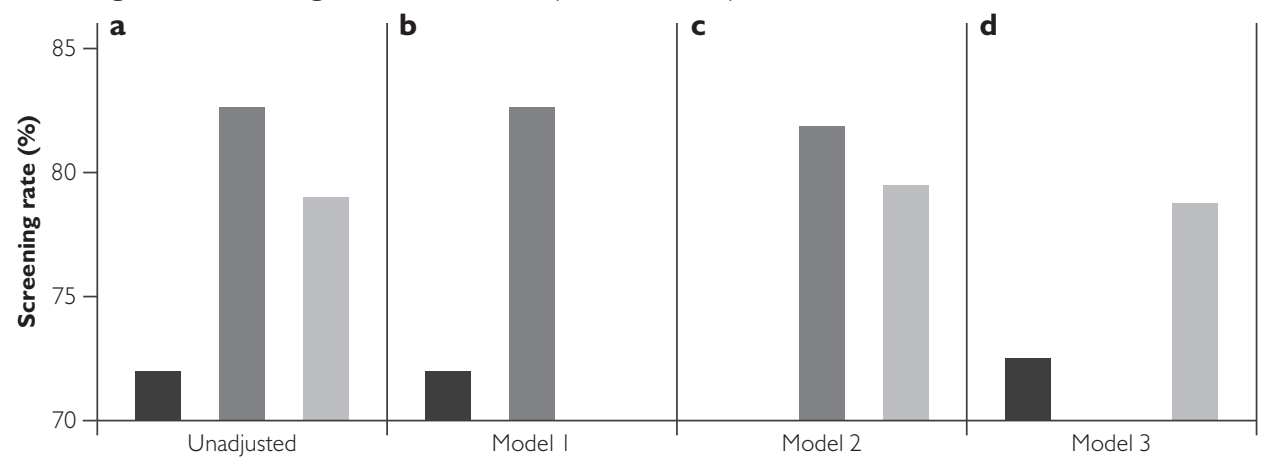

FFS $=$ fee-for-service; FHG = Family Health Group; FHO = Family Health Organization. 
TABLE 3. Average costs of delivering cervical cancer screening by primary care practice model, including bonus payments where eligible

\begin{tabular}{|l|l|l|l|l|}
\hline & FFS & FHG & FHO & Total \\
\hline Bonuses claimed, N (\%) & - & $1,590(55.8 \%)$ & $2,657(81.0 \%)$ & $4,247(69.3 \%)$ \\
\hline Annual Paps, N & 52,774 & 233,134 & 271,241 & 557,149 \\
\hline Pap smear delivery costs* & $\$ 965,764$ & $\$ 4,266,352$ & $\$ 4,963,710$ & $\$ 10,195,827$ \\
\hline Total bonus payments & - & $\$ 2,660,240$ & $\$ 4,534,640$ & $\$ 7,194,880$ \\
\hline Total annual costs & $\$ 965,764$ & $\$ 6,926,592$ & $\$ 9,498,350$ & $\$ 17,390,708$ \\
\hline $\begin{array}{l}\text { Average cost per woman } \\
\text { screened }\end{array}$ & $\$ 18.30$ & $\$ 29.71$ & $\$ 35.02$ & $\$ 31.21$ \\
\hline Marginal cost & $\$ 18.30$ & $\$ 33.05$ & $\$ 39.06$ & - \\
\hline
\end{tabular}

FFS = fee-for-service; FHG = Family Health Group; FHO = Family Health Organization.

*Annual costs of delivering Pap smears, where one Pap smear is valued at $\$ 18.30$.

\section{Discussion}

Our results show significant differences in cervical cancer screening rates between the traditional FFS model and two dominant reformed primary care practice models. Physicians practising in a FHG or FHO tend to have significantly higher screening rates compared with those in the traditional FFS model, suggesting that practising in a patient enrolment model with financial incentives is associated with higher cervical cancer screening rates. FHG screening rates were significantly higher than the FHO, but the difference was modest $(<3 \%)$. The average cost and marginal cost were highest in the FHO, followed by the FHG and then the FFS model. However, the average cost in the FHO decreased from $\$ 35.02$ in the primary analyses to $\$ 29.22$ in the sensitivity analysis, which was lower than the average cost in the FHG (\$29.71). Our results suggest that eligibility for financial incentives combined with a FFS payment scheme is associated with higher cervical screening rates. This is supported by the economic theory that FFS physicians have an incentive to provide a high volume of services (Devlin et al. 2006; Robinson 2001). Physicians in a capitation system may be incentivized to reduce services, because they do not receive reimbursement for additional services.

Our results show higher screening rates than reported for women aged 20-69 who are eligible for screening (Cancer Care Ontario 2014). This difference may be due to differences in study populations as women aged 20-29 have lower screening participation than women aged 30-69 years (Cancer Care Ontario 2014). Furthermore, this study included women who were active patients of FFS physicians or enrolled in a FHG or FHO. Patients with access to a regular family physician may be more health conscious and more likely to be screened than those without (Hsia et al. 2000; Qi et al. 2006). Our findings of higher screening rates in the reformed models is generally consistent with previous research, suggesting that incentives are associated with modest uptake in cervical cancer screening 
Financial Incentives and Cervical Cancer Screening Participation in Ontario's Primary Care Practice Models

rates (Eijkenaar et al. 2013). A previous analysis of financial incentives in Ontario estimated that the screening bonus increased absolute Pap smear compliance by 4.1 percentage points (Li et al. 2014). Our finding of a 6.2-7.7\% difference between the FFS and reformed practice models with incentives is higher; however, our study period is three years after that of Li et al. (2014). Another Ontario study reported that within two years of joining a FHG or a blended capitation model similar to the FHO, cervical cancer screening increased by $1.9 \%(p<0.001)$ and 4.6\% ( $p<0.001)$, respectively (Jaakkimainen et al. 2011). However, a more recent longitudinal analysis found no difference in trends of screening rates before and after the introduction of the incentive (Kiran et al. 2014). Our results build upon previous research by highlighting the differences in screening rates between the traditional FFS and patient enrolment models with incentive eligibility, as well as making direct comparisons between reformed models with different base remuneration. Prior research in Ontario found no difference in cervical cancer participation between the FHG and blended capitation Family Health Network (Jaakkimainen et al. 2011) and that remuneration was not significantly associated with preventive care manoeuvres including Pap smears (Dahrouge et al. 2012). However, another study suggested that rates in the FHO are higher as FHO physicians were $10.3 \%$ more likely to claim a Pap smear bonus than those in FHGs (Kralj and Kantarevic 2013).

This paper has several strengths. Our results contribute to the evolving literature on the roles of primary care organization, delivery and remuneration on quality of care by comparing cervical cancer screening rates in the traditional FFS and two reformed practice models in Ontario. These analyses highlight the association between incentive eligibility and physician behaviour by estimating practice screening rates rather than individual screening status as an outcome variable. Financial incentives are directed toward physicians not patients, so their impact on clinical practice is meaningful at the physician level rather than at the patient level. We examined the influence of incentives across different primary care practice models with distinct funding arrangements in contrast to previous research that considered all practice models eligible for incentives as one group (Kiran et al. 2014; Li et al. 2014). Finally, we examined both screening rates and costs to better understand the impact of recent reforms in primary care on cervical cancer screening.

This analysis also has several limitations. First, we were unable to assess temporal trends in cervical cancer screening rates. Second, our estimates of screening rates in the FHO may be biased downward if FHO physicians practising in hospitals do not submit shadow billings. Third, we assumed that Pap smear delivery costs (excluding bonus payments) in the FHO model were equal to those in the FFS and FHG models to simplify cost calculations. However, this assumption may not hold true depending on a woman's use of the healthcare system. For example, the proportion of capitation payments attributed to screening would be higher for a woman who only sees her family physician once every three years for a Pap test than a sicker woman who sees her physician more frequently. Without knowing the healthcare utilization of $\mathrm{FHO}$ patients, we were unable to assess the impact 
of this assumption on screening cost estimates. We attempted to explore this through sensitivity analysis by varying the delivery cost in the $\mathrm{FHO}$, which resulted in a lower average cost per woman screened in the FHO than FHG under some scenarios. Fourth, the switch from the FFS to a reformed practice model was voluntary; physicians joining a FHG or FHO may differ systematically by provider behaviour or other unknown physician characteristics. Although we controlled for several observable physician and patient characteristics, there may be selection bias based on some unobservable factors. Prior to joining a FHG, physicians had greater productivity than those who did not switch (Kantarevic et al. 2011), and physicians with complex and less affluent patients were more likely to join a FHG than remain in the FFS model (Kantarevic et al. 2011) or join a capitation-based model (Rudoler et al. 2014). Differences in physician productivity and patient populations may differentially affect screening rates across practice models and potentially bias our results. Finally, women identified as patients of FFS physicians may have seen a FFS physician for acute needs rather than ongoing care. We were unable to identify FFS physicians practicing in walk-in clinics with patients who come and go from their practice, which may explain lower screening rates.

\section{Conclusions}

Ontario's reforms shifted the primary care landscape from solo private practice reimbursed on a FFS basis toward group-based practices with formal patient enrolment and incentives for preventive care. Our results demonstrate that significant differences in cervical cancer screening rates exist across the traditional FFS and reformed practice models featuring patient rostering and incentives have significantly higher screening rates, as well as higher average and marginal costs. Our results contribute to the growing body of empirical evidence on the role of remuneration and incentives on quality, and may be useful for policy decisions.

\section{Acknowledgements}

The authors would like to thank Dr. Rick Glazier, Alex Kopp and Nathaniel Jembere at the Institute for Clinical Evaluative Sciences (ICES) and Dr. Salimah Shariff and ICES Western. This study was supported by ICES, which is funded by an annual grant from the Ontario Ministry of Health and Long-Term Care (MOHLTC). This study was part of a larger project funded by the Canadian Institutes of Health Research Operating Grant (MOP-130454). The opinions, results and conclusions reported in this paper are those of the authors and are independent from the funding sources. No endorsement by ICES or the Ontario MOHLTC is intended or should be inferred.

Correspondence may be directed to: Sisira Sarma, Western University, Kresge Building, Room K201, London, ON N6A 5C1; tel.: 519-661-2111, ext.87583; e-mail: ssarma2@uwo.ca. 


\section{References}

Andrae, B., L. Kemetli, P. Sparen, L. Silfverdal, B. Strander, W. Ryd et al. 2008. "Screening-Preventable Cervical Cancer Risks: Evidence from a Nationwide Audit in Sweden." Journal of the National Cancer Institute 100(9): 622-29. doi:10.1093/jnci/djn099.

Antoniou, T., B. Zagorski, M.R. Loutfy, C.S. Strike and R.H. Glazier. 2011. "Validation of Case-Finding Algorithms Derived from Administrative Data for Identifying Adults Living with Human Immunodeficiency Virus Infection." PLoS ONE 6(6): e21748. doi:10.1371/journal.pone.0021748.

Canadian Cancer Society's Advisory Committee on Cancer Statistics. 2013. Canadian Cancer Statistics 2013. Toronto, ON: Canadian Cancer Society. Retrieved February 21, 2015. <http://www.cancer.ca/ /media/cancer. ca/CW/cancer\%20information/cancer\%20101/Canadian\%20cancer\%20statistics/canadian-cancer-statistics2013-EN.pdf>.

Canadian Task Force on Preventive Health Care, J. Dickinson, E. Tsakonas, S. Conner Corber, G. Lewin, E. Shaw et al. 2013. "Recommendations on Screening for Cervical Cancer." Canadian Medical Association Journal 185(1): 35-45. doi:10.1503/cmaj.121505.

Cancer Care Ontario. 2014. Ontario Cervical Screening Program 2012 Report. Toronto, ON: Cancer Care Ontario. Retrieved February 21, 2015. <https://www.cancercare.on.ca/common/pages/UserFile. aspx?fileId $=295748>$.

Dahrouge, S., W.E. Hogg, G. Russell, M. Tuna, R. Geneau, L.K. Muldoon et al. 2012. “Impact of Remuneration and Organizational Factors on Completing Preventive Manoeuvres in Primary Care Practices." Canadian Medical Association Journal 184(2): E135-43. doi:10.1503/cmaj.110407.

Devlin, R.A., S. Sarma and W. Hogg. 2006. "Remunerating Primary Care Physicians: Emerging Directions and Policy Options for Canada." Healthcare Quarterly 9(3): 34-42.

Dickinson, J.A., A. Stankiewicz, C. Popadiuk, L. Pogany, J. Onysko and A.B. Miller. 2012. "Reduced Cervical Cancer Incidence and Mortality in Canada: National Data from 1932 to 2006." BMC Public Health 12: 992. doi:10.1186/1471-2458-12-992.

Eijkenaar, F., M. Emmert, M. Scheppach and O. Schoffski. 2013. "Effects of Pay for Performance in Health Care: A Systematic Review of Systematic Reviews." Health Policy 110(2-3): 115-30. doi:10.1016/j.healthpol.2013.01.008.

Ferlay, J., H.R. Shin, F. Bray, D. Forman, C. Mathers and D.M. Parkin. 2010. "Estimates of Worldwide Burden of Cancer in 2008: GLOBOCAN 2008.” International Journal of Cancer 127(12): 2893-917. doi:10.1002/ijc.25516.

Glazier, R.H., B.M. Zagorski and J. Rayner. 2012. Comparison of Primary Care Models in Ontario by Demographics, Case Mix and Emergency Department Use, 2008/09 to 2009/10 (ICES Investigative Report).

Toronto, ON: Institute for Clinical Evaluative Sciences. Retrieved February 21, 2015. <http://www.ices.on.ca/ / media/Files/Atlases-Reports/2012/Comparison-of-primary-care-models-in-Ontario/Full\%20report.ashx>.

Government of Ontario; Ministry of Health and Long Term Care. 2014. Schedule of Benefits for Physician Services under the Health Insurance Act. Retrieved February 21, 2015. <http://www.health.gov.on.ca/english/ providers/program/ohip/sob/physserv/physserv_mn.html>.

Hsia, J., E. Kemper, C. Kiefe, J. Zapka, S. Sofaer, M. Pettinger et al. 2000. "The Importance of Health Insurance as a Determinant of Cancer Screening: Evidence from the Women's Health Initiative." Preventive Medicine 31(3): 261-70.

Hutchison, B.G., J. Hurley, S. Birch, J. Lomas and F. Stratford-Devai. 1997. “Defining the Practice Population in Fee-for-Service Practice." Health Services Research 32(1): 55-70.

Jaakkimainen, R.L., J. Barnsley, J. Klein-Geltink, A. Kopp and R.H. Glazer. 2011. “Did Changing Primary Care Delivery Models Change Performance? A Population Based Study Using Health Administrative Data." BMC Family Practice 12: 44. doi:10.1186/1471-2296-12-44.

Jemal, A., F. Bray, M.M. Center, J. Ferlay, E. Ward and D. Forman. 2011. “Global Cancer Statistics." CA: A Cancer Journal for Clinicians 61(2): 69-90. doi:10.3322/caac.20107.

Kantarevic, J., B. Kralj and D. Weinkauf. 2011. “Enhanced Fee-for-Service Model and Physician Productivity: Evidence from Family Health Group in Ontario." Journal of Health Economics 30(1): 99-111. doi:10.1016/j.jhealeco.2010.10.005. 
Kiran, T., A.S. Wilton, R. Moineddin, L. Paszat and R.H. Glazier. 2014. “Effect of Payment Incentives on Cancer Screening in Ontario Primary Care." Annals of Family Medicine 12(4): 317-23. doi:10.1370/afm.1664.

Kralj, B. and J. Kantarevic. 2013. "Quality and Quantity in Primary Care Mixed-payment Models: Evidence from Family Health Organizations in Ontario." Canadian Journal of Economics 46(1): 208-38. doi:10.1111/caje.12003.

Li, J., J. Hurley, P. DeCicca and G. Buckley. 2014. “Physician Response to Pay-for-Performance: Evidence from a Natural Experiment." Health Economics 23(8): 962-78. doi:10.1002/hec.2971.

Lofters, A.K., R. Moineddin, S.W. Hwang and R.H. Glazier. 2010. "Low Rates of Cervical Cancer Screening among Urban Immigrants: A Population-Based Study in Ontario, Canada." Medical Care 48(7): 611-18. doi:10.1097/MLR.0b013e3181d6886f.

Macgregor, J.E., M.K Campbell, E.M. Mann and K.Y. Swanson. 1994. “Screening for Cervical Intraepithelial Neoplasia in North East Scotland Shows Fall in Incidence and Mortality from Invasive Cancer with Concomitant Rise in Preinvasive Disease." BMJ 308(6941): 1407-11.

Matheson, F.I., J.R. Dunn, K.L. Smith, R. Moineddin and R.H. Glazier. 2012. “Development of the Canadian Marginalization Index: A New Tool for the Study of Inequality." Canadian Journal of Public Health 103(8 Suppl 2): S12-16.

Muller, C.J. and R.F. MacLehose. 2014. "Estimating Predicted Probabilities from Logistic Regression: Different Methods Correspond to Different Target Populations." International Journal of Epidemiology 43(3): 962-70. doi:10.1093/ije/dyu029.

Murphy, J., E.B. Kennedy, S. Dunn, C.M. McLachlin, M. Fung Kee Fung, D. Gzik et al. 2012. “Cervical Screening: A Guideline for Clinical Practice in Ontario." Journal of Obstetrics and Gynaecology Canada 34(5): 453-58.

Office of the Auditor General of Ontario. 2011. Funding Alternative for Family Physicians. 2011 Annual Report. Toronto, ON: Queen's Printer for Ontario. Retrieved February 21, 2015. <http://www.auditor.on.ca/en/ reports_en/en11/306en11.pdf>.

Papke, L.E. and J.M. Woodbridge. 1996. "Econometric Methods for Fractional Response Variables with an Application to 401 (K) Plan Participation Rates." Journal of Applied Econometrics 11(6): 619-32. doi:10.1002/ (SICI)1099-1255(199611)11:6<619::AID-JAE418>3.0.CO;2-1.

Pendrith, C. 2014. The Impact of Financial Incentives for Cervical Cancer Screening in Ontario's Primary Care Delivery Models. Unpublished master's thesis, Western University. London, ON.

Qi, V., S.P. Phillips, W.M. Hopman. 2006. "Determinants of a Healthy Lifestyle and Use of Preventive Screening in Canada." BMC Public Health. 6: 275. doi:10.1186/1471-2458-6-275.

Robinson, J.C. 2001. "Theory and Practice in the Design of Physician Payment Incentives." Milbank Quarterly 79(2): 149-77, III.

Rudoler, D., R. Deber, J. Barnsley, R.H. Glazier and A. Laporte. 2014. Paying for Primary Care: The Factors Associated with Physician Self-Selection into Payment Models. Working Paper No. 2014-06. Retrieved February 21, 2015. <http://www.canadiancentreforhealtheconomics.ca/wp-content/uploads/2014/07/Rudoler-et-al.pdf>.

Schiffman, M., P.E. Castle, J. Jeronimo, A.C. Rodriguez and S. Wacholder. 2007. "Human Papillomavirus and Cervical Cancer." Lancet 370(9590): 890-907.

Spayne, J., I. Ackerman, M. Milosevic, A. Seidenfeld, A. Covens and L. Paszat. 2008. “Invasive Cervical Cancer: A Failure of Screening." European Journal of Health Economics 18(2): 162-65.

Spence, A.R., P. Goggin and E.L. Franco. 2007. "Process of Care Failures in Invasive Cervical Cancer Systematic Review and Meta-Analysis." Preventive Medicine 45(2-3): 93-106.

Sweetman, A. and G. Buckley. 2014. "Ontario's Experiment with Primary Care Reform." University of Calgary School of Public Policy SPP Research Papers 7(11): 1-38. 